\title{
New Quantitative Method to Estimate Students’ Responsibility Toward Learning a Class
}

\author{
Uladzimir Shtukar \\ North Carolina Central University, Durham, USA
}

\begin{abstract}
A new quantitative evaluation method is proposed to determine a student's responsibility grade in any class. The grade is an assessment of the extent to which a student performed his/her responsibilities toward succeeding in a class. Each grade is estimated from five equally weighted factors that are introduced herein as a basis for any evaluation. The implication of students' responsibility grades on their final grades is analyzed for classes taught by the author. Responsibility grades of $70 \%$ and higher are found to guarantee a passing course grade (A, B, or C) for most of the undergraduate students and for all graduate students.
\end{abstract}

Keywords: students' responsibility, new quantitative evaluation method, responsibility grade

\section{Introduction}

All faculty and administrators agree that higher education is designed to develop students into professionals by the time of graduation. The essential challenge is how a college or university can achieve this important goal. This problem has a complicated solution; to solve it, colleges and universities must first solve another problem: how to motivate students to learn the taught material in their courses. One of the key factors affecting a student's success in class is his or her level of responsibility. The following authors use qualitative methods to analyze a typical student's responsibility as responsibility of college membership (Davis \& Murrell, 1993; Pace, 1990). Todd Davis and Patricia Murrell (1993) write, "Student responsibility is a key to all development and learning", in their article, in which they provide a qualitative description of a typical student's responsibility. Robert Pace (1990) defines a typical student's responsibility and provides an appropriate classification of this responsibility based on a questionnaire. Some authors (Devlin, 2002; Hassel \& Lourey, 2005) analyze more specific types of student responsibility to learn using qualitative methods. Marcia Devlin (2002) analyzes students' conceptions of learning utilizing a questionnaire for which students characterize their responsibilities by themselves. The last survey informs us that $56 \%$ of students understand their personal responsibilities to learn. Unfortunately, students' declared personal responsibilities are not their actual responsibilities performed. Some students very clearly understand their personal responsibility to learn but sometimes demonstrate a weak actual responsibility. The standard qualitative survey concerning students' responsibilities was conducted in one of the author's classes in the middle of the fall semester of 2013, the results of which have shown that $91 \%$ of students thought that they were responsible for their own learning. After that survey, those same students' responsibilities were estimated by the author's quantitative method, showing that just $52 \%$ of students were actually responsible. The difference between these results demonstrates

Uladzimir Shtukar, Ph.D., Assistant Professor, Math/Physics Department, North Carolina Central University. 
that qualitative methods, such a questionnaire, do not guarantee accurate evaluations of students' personal responsibilities, but the new quantitative method does.

\section{Definition}

To analyze a student's responsibility accurately, we must introduce the basic definition for responsibility. We define a student's responsible behavior to learn a course as the behavior that satisfies the following requirements: attend all classes, arrive to class on time, perform all tests and quizzes, complete all homework assigned, ask an instructor or a tutor for help when needed, perform positively in the classroom by listening to instructor, ask questions for better understanding, and write personal notes.

Administrators and faculty at any college should know the students' real responsibilities to help students form their best personal responsibilities during the educational process. In other words, a quantitative method is needed to accurately evaluate a student's responsibility to learn.

In this article, a quantitative method will be introduced to grade a student's responsibility to learn material in any class. This type of student responsibility is more specific than the general student responsibility, which includes out-of-class responsibilities such as meeting with his/her advisor regularly and attending college events. Student's responsibility to learn deserves more concerted research efforts because if we ignore students' responsibilities to learn, we have no hope for educating students who will perform responsibly as professionals.

Measurement of a student's responsibility result of a traditional qualitative survey utilizing questionnaire may be very far from the correct assessment of a student's responsibility performance. Now, we begin to construct an effective quantitative method to estimate a student's responsibility performance to learn. What type of information can be used as a basis for accurate analysis of a student's responsibility performance? Some objective data from the class statistics should be used to compute "the responsibility grade" for each student. All instructors keep track of students' attendance, homework, test results, and quiz results (traditional factors). These data are acceptable according to the definition, so they should be used in any evaluation method. One additional factor that reflects a student's drive to learn is the number of visits a student makes to a tutoring center or to his/her instructor for help. Why? Make-up tests and quizzes are available for students in many universities/colleges, and students usually perform them in an instructor's office. The author has implemented a new instructor-student collaboration model in the educational process; this model stimulated students' visits to the instructor's office, and all of these visits were documented for analysis. Therefore, this non-traditional factor characterizes students' activity for learning outside of class, and it can be utilized for computing the responsibility grade. Another non-traditional factor that should be included in each responsibility grade is any positive or negative activity of a student during class. Negative activities include talking, eating, drinking, sleeping, and using a cell phone or other electronic device. Positive activities include listening to the instructor, participating in some discussions initiated by instructor, asking questions, and writing notes during class. This information should be also collected during each class meeting and used for the evaluation of the responsibility grade because these activities characterize a student's responsibility to learn in class. The author is sure that these factors are important for a good student's responsibility, especially the positive student activity inside of a classroom. The positive activity is likely the most important for a student's responsibility, but this assumption requires additional research.

The traditional and non-traditional factors listed above can be used to compute the following five numbers: (1) number of classes with very late attendance or missed entirely; (2) number of tests or quizzes missed; (3) 
number of homework assignments failed or missed; (4) number of student visits to the instructor or learning center; and (5) number of classes with positive student activity. These numbers are not on the same scale (4 classes missed are not equal to 4 tests missed), and they do not have the same polarity: high values at the 1st, 2nd, and 3rd positions characterize non-responsible performance, where as high values at the 4th and 5th positions characterize responsible performance. This problem can be fixed as follows: replace factors 1,2 , and 3 with associated complimentary percentages: $r_{1}=$ the percent of classes attended on time; $r_{2}=$ the percent of tests and quizzes taken on time; $r_{3}=$ the percent of homework completed. Replace 4 with: $r_{4}=$ the percent of the number of student visits with respect to the number of chapters studied in the course, or $100 \%$ if the number of visits exceeds the number of chapters. Replace 5 with: $r_{5}=$ the percent of classes with a positive student activity.

We are now well equipped to introduce the student responsibility grade. All five factors are meant to be equally important for the ideal responsibility performance. Thus, the final responsibility grade $r$ is defined to be the average of all factors

$$
r=\frac{1}{5}\left(r_{1}+r_{2}+r_{3}+r_{4}+r_{5}\right)
$$

\section{Assessment of the Measure}

The author taught two types of classes during the 2010-2011, 2011-2012, 2012-2013, and 2013-2014 academic years. The first type was Finite Mathematics classes (see Table 1), which consisted almost entirely of freshmen and sophomores. The second type was Linear Algebra and Geometry classes (see Table 2), which consisted of juniors and seniors. The influence of responsibility performance on the course grade was assessed separately for both class types utilizing the following idea: responsibility grades were determined by the author's method for all students who finished the courses. Thereafter, students were assigned to one of two groups: having grades greater or equal $70 \%$, and having grades less than $70 \%$. The cut-off point of $70 \%$ is selected as the traditional level in education.

Table 1

Number of Students Who Finished Author's Finite Mathematics Classes in 2010-2014 Academic Years

\begin{tabular}{llll}
\hline $\begin{array}{l}\text { Number of students } \\
\text { who passed classes }\end{array}$ & $\begin{array}{l}\text { Total number of students in the } \\
\text { classes }\end{array}$ & $\begin{array}{l}\text { Students with responsibility } \\
\text { grade } \geqslant 70\end{array}$ & $\begin{array}{l}\text { Students with responsibility } \\
\text { grade }<70\end{array}$ \\
\hline $\begin{array}{l}\text { Number of students } \\
\text { who passed classes }\end{array}$ & 201 & 114 & 87 \\
$\begin{array}{l}\text { Number of students } \\
\text { who didn't pass classes }\end{array}$ & 81 & 100 & 20 \\
\hline
\end{tabular}

Refer to the Table 1, only 57\% (114/200) of the freshman and sophomore students performed responsibly. This finding is consistent with the result (Devlin, 2002) that was mentioned in the introduction. However, the most important finding is that performing responsibly almost guarantees passing the class, and not performing responsibly almost guarantees failing the class: $87.7 \%$ (100/114) of the freshmen and sophomore responsible students passed, but only $23.0 \%$ (20/87) of those with poor responsibility grades passed.

Referring to Table 2, we see that $87.7 \%(84 / 89)$ of the junior and senior students performed their learning duties with good responsibility, which is $30.7 \%$ better than for the freshman/sophomore students. More essentially, for the high level students, good responsibility grade guarantees passing the course: $100 \%(73 / 73)$ 
of the junior and senior responsible students passed. In addition, only $68.8 \%(11 / 16)$ of students with poor responsibility grades passed.

Table 2

The Number of Students Who Finished Author's Linear Algebra and Geometry Classes in 2010-2014 Academic Years

\begin{tabular}{|c|c|c|c|}
\hline & $\begin{array}{l}\text { Total number of students in the } \\
\text { classes }\end{array}$ & $\begin{array}{l}\text { Students with responsibility grade } \\
\geqslant 70 \%\end{array}$ & $\begin{array}{l}\text { Students with responsibility grade } \\
<70 \%\end{array}$ \\
\hline & 89 & 73 & 16 \\
\hline $\begin{array}{l}\text { Number of students who } \\
\text { passed classes }\end{array}$ & 84 & 73 & 11 \\
\hline $\begin{array}{l}\text { Number of student who } \\
\text { didn't pass classes }\end{array}$ & 5 & 0 & 5 \\
\hline
\end{tabular}

\section{Summary}

The new quantitative method is a valid instrument that all instructors and professors may use to analyze a student's responsibility performance in any class, at any time during a semester. Utilizing this method, instructors and professors will know what type of students they have in their classes. They may then adapt appropriate strategies to motivate their students and help them to improve their responsibility performance. A student's responsibility grade will persuade the student regarding his/her responsibility much more strongly than any simple declaration about his/her current responsibility. Remember that students believe in a formal evaluation of their responsibility rather than in wordy description. According to the evaluation performed, they will see which parts of their responsibility are week, and they will have a chance to improve their responsibility.

The author hopes that this method will be utilized at other colleges and universities to compare the new results with those presented here. As a fundamental step in higher education, the author proposes to introduce the official responsibility grades for all students in some basic classes in each college/university.

\section{Remarks}

(1) The special grade $r_{4}$ looks strange but it is necessary to measure a student's activity to learn after class. Its structure is unusual, but different attempts to substitute it by another measured factor were not successful.

(2) The author does not observe all existing qualitative methods concerning a responsibility, so, only a few references that are cited in the manuscript are included at the list.

\section{References}

Davis, T., \& Murrell, P. (1993). Turning teaching into learning: The role of student responsibility in the collegiate experience (ASHE-ERIC Higher Education Reports, Report No.1). Washington, DC: The George Washington University, School of Education and Human Development.

Devlin, M. (2002). Taking responsibility for learning isn't everything: A case for developing tertiary students' conceptions of learning. Teaching in Higher Education, 7(2), 125-138.

Hassel, H., \& Lourey, J. (2005). The dea(r)th of student responsibility. College Teaching, 53(1), 2-13.

Pace, R. (1990). The undergraduates: A report of their activities and progress in college in the 1980s. Los Angeles: UCLA Center for the Study of Evaluation. 